\title{
Association between visual impairment and depression in the elderly: a systematic review
}

\author{
Associação entre deficiência visual e depressão em idosos: uma revisão sistemática
}

Marina Viegas Moura Rezende Ribeiro ${ }^{1}$, Hermann Nogueira Hasten-Reiter Júnior ${ }^{1}$, Eurica Adélia Nogueira Ribeiro ${ }^{1}$, Mario Jorge Jucáa ${ }^{1}$, Fabiano Timbó Barbosa ${ }^{1}$, Célıo Fernando de Sousa-Rodrigues ${ }^{1}$

\begin{abstract}
A systematic review was conducted to investigate the relationship between visual impairment and depression in the elderly. We searched electronic databases (LILACS, SciELO, MEDLINE, and Cochrane Central Register of Controlled Trials) from inception to August 2014 and researched the described references. The search strategy used the following terms: (visual impairment or blindness) and (elderly) and (depression). Of the 641 electronics, 42 works were selected in full and another 20 were identified as being possibly relevant. Ten studies were included. The studies ranged in sample size from 31 to 21,995 participants. Depression was associated with visual impairment in all studies; however, without standardization of diagnostic tests, we could not conduct a meta-analysis or establish a relationship between visual impairment and depression in the elderly.
\end{abstract}

Keywords: Visual impairment; Depression; Aging; Blindness; Vision loss

\section{RESUMO}

A revisão sistemática foi realizada para investigar a correlaçõa entre deficiência visual e depressão em idosos. Foram pesquisados nas bases eletrônicas (LILACS, SCIELO, MEDLINE e Cochrane Central Register of Controlled Trials) do início até agosto de 2014 e pesquisas de referências descritas. A estratégia de busca utilizou os termos: (deficiência visual ou cegueira) e (idosos) e (depressão). Dos 641 eletrônicos, 42 trabalhos na integra foram selecionados e mais 20 trabalhos foram identificados como possivelmente relevantes da lista destes. Do total de estudos, 10 foram incluidos. Os estudos variaram entre 31 e 21.995 participantes. A depressão foi relacionada com deficiência visual em todos os estudos, mas sem padronização de testes diagnósticos não foi possível realizar a metanálise, nem estabelecer relação entre deficiência visual e depressão em idosos.

Descritores: Deficiência visual; Depressão; Idoso; Cegueira; Perda visual

\section{INTRODUCTION}

Visual impairment $(\mathrm{VI})$ is becoming a major public health concern with the aging of the population. It is the third most prevalent physical impairment among older adults ${ }^{(1)}$. Visual impairment affects one-third of elderly subjects, with the prevalence of mild or severe VI ranging from $4 \%$ to $12 \%(2,3)$. Ultimately, untreated eye disorders can contribute to avoidance of social situations, resulting in social isolation or leading to substantial physical decline, which may ultimately require a transition into an assisted living arrangement ${ }^{(4)}$. A number of studies suggest that disability may contribute to depression ${ }^{(5)}$; depression is the most common psychiatric disorder and carries a high burden in terms of treatment costs, effect on families and carers, as well as loss of workplace productivity ${ }^{(6)}$. The World Health Organization (WHO) currently ranks it as the third most prevalent moderate and severe disabling condition globally. It may become a chronic disorder with ongoing disability, particularly if inadequately treated, contributing to the global burden of disease ${ }^{(7)}$. Results from a number of population-based ${ }^{(8-12)}$ and hospital-based studies ${ }^{(13,14)}$ indicate that $\mathrm{VI}$ is associated with higher rates of depression.

This review aimed to verify whether there is an association between $\mathrm{VI}$ and depression in the elderly.

\section{METHODS}

The PRISMA guidelines ${ }^{(15)}$ were followed for this review, and the sections below are set out according to these guidelines.
Articles that reported depression, as analyzed by the Geriatric Depression Score (GDS) or another specific scale, in adults aged 65 years and older with VI (visual acuity worse or equal to $20 / 70$ or 0.55 in logMAR) or mild VI (visual acuity worse than 20/40 or 0.3 in logMAR) were included ${ }^{(16)}$. Cross-sectional, cohort studies, or case-control studies were also included. Any setting was permitted (primary care, secondary care, or general population), although the search was limited to articles in English or Portuguese. Review studies, unpublished articles, abstracts, theses, dissertations, and book chapters were not included. Articles regarding dual sensory loss (hearing and VI) were excluded, as were studies about a single ocular disease and those not reporting about $\mathrm{VI}$ as the primary objective.

The primary outcomes associated with the aim of this review were depression, most frequently evaluated using $\mathrm{GDS}^{(17)}$ or the Center for Epidemiologic Studies-Depression scale (CES-D) ${ }^{(18)}$ and visual acuity. Secondary outcomes analyzed included sociodemographic variables (age, gender, marital status, ethnicity, years of education, living alone or not, social activities), visual function (VF questionnaires), visual field, disability [analyzed by the Community Disability Score (CD-30) or Activities of Daily Living (ADL)], chronic disease, mortality, anxiety [measured using the State-Trait Anxiety Index (STAI-6) or General Health Questionnaire Score (GHQ-28)], physical activity, quality of life [measured using Short-Form Health Surveys (SF)], number of antidepressive medications, previous history of depression, duration of institutionalization if present, and duration of VI.

To gather as many studies as possible on the issue, the strategy for data collection aimed to identify articles that presented the de-
Submitted for publication: January 20, 2015

Accepted for publication: April 6, 2015

Universidade Federal de Alagoas (UFAL), Maceió, AL, Brazil.
Funding: No specific financial support was available for this study.

Disclosure of potential conflicts of interest: None of the authors have any potential conflict of interest to disclose.

Corresponding author: Marina Moura Rezende. Rua Prefeito Abdon Arroxelas, 219/303 - Maceió, AL - 57035-380 - Brazil - Email: dra.marinaribeiro@gmail.com 
finition of $\mathrm{VI}$ and depression in the elderly. The following electronic databases [LILACS, SciELO, MEDLINE (via PUBMED), and Cochrane Central Register of Controlled Trials (CENTRAL)] were searched, from inception to August 2014. Two independent reviewers conducted the search using the same keywords. The search strategy used the following terms: (visual impairment OR blindness) and (elderly) and (depression). Cited references were also evaluated.

Abstracts thought to be relevant were retrieved for closer inspection. If meeting the inclusion criteria, the full text of the article was located. The reference lists of all full-text articles identified during the electronic search were scanned for further articles that may be relevant. In addition, we scanned all related references of the full-text articles meeting the inclusion criteria. Data were independently extracted by two reviewers to ensure accuracy using a standard data table extraction that includes details about the studies such as name, author, year, periodical and database, country, number of participants, study design, variables, limitations, and main results. All included studies were subjected to methodological critical appraisal using the Cochrane Collaboration of risk of bias: the Newcastle-Ottawa Scale, adapted version ${ }^{(19)}$. The original Newcastle-Ottawa Scale ${ }^{(20)}$ is used to analyze quality in observational studies. It has eight questions that access three dimensions: selection, comparability, and results (in cohort studies) or exposition (case-control studies). For each question, there are several options, and each option that is associated with the best quality is scored with a star; the more stars a study has, the better is its quality.

In this review, the questions were adapted to investigate exposition and outcome (depression), and the risk of bias was classified as low, unknown, and high risks; each star represents a low risk of bias. Two independent reviewers assessed the quality of studies.

For dichotomous outcomes, we intended to use the odds ratio (OR) and 95\% confidence interval (Cl) calculated using a random-effect model (REM). When the effect is absent, the risk difference (RD) and $95 \% \mathrm{Cl}$ is calculated using REM. For continuous outcomes, the mean and standard deviation are used to generate the mean difference (MD) and 95\% Cl using REM. BioEstat version 5.3 was used to conduct meta-analyses. Statistical heterogeneity $\left({ }^{2}\right)$ was assessed using heterogeneity tests, i.e., the standard chi-square test ( $p$ value $<0.10$ or $<10 \%)$ and the $R^{2}$ test $\left({ }^{2}>50 \%\right.$ was considered statistically significant).

\section{RESULTS}

\section{Study Selection}

Of the 641 search results, 42 full-text articles were retrieved. The reference lists of each of these articles were scanned, and further 20 articles were identified as being possibly relevant. Of the total studies identified, 10 were considered relevant and have been evaluated (Figure 1).

\section{StUdy CHARACTERISTICS}

A summary of the main results of the review is presented in table 1. Of the 10 studies included, the number of participants ranged from 31 to 21,995); two were conducted in the United States, two in Canada, one in New Zealand, one in France, two in China, one in Malaysia, and one in England. Five of the articles reported cohort studies and five others were cross-sectional studies. According to the Newcastle-Ottawa Scale, most articles had a low bias risk (Table 2).

\section{Measures of depression}

Depression was measured using a number of different tools, the most popular being GDS-15, used in eight studies. GDS-15is a self-administered questionnaire consisting of 15 items that are related to depression. It was specifically developed for older people and places less emphasis on somatic symptoms than other generic depression scales. It asks respondents to answer "yes" or "no" to 15 questions about how they have felt in the past week. GDS-15 is a screening tool for depression rather than an assessment scale providing a clinical diagnosis of depression; the level of depressive symptomatology is related to the level of depression. In these studies, the cut-off for depression ranged into four or more ${ }^{(21)}$, five or more ${ }^{(22,23)}$, six or more $e^{(24-26)}$, and 11 or more(27). Another questionnaire that was used was CES-D, used in two studies ${ }^{(4,12)}$. CES-D records the frequency and severity of depressive symptoms over the preceding week via a 20 -item questionnaire. Each item is scored on a scale from 0 (less than 2 days duration) to 3 (5-7 days, both days inclusive), and a score of 16 or more indicates major depression. One of the studies ${ }^{(28)}$ used depression diagnosis based on the International Diseases Code (ICD-10). Because of this heterogeneity, meta-analysis was not possible with this variable.

\section{Measures of Visual acuity}

Visual acuity was presented as logMAR, decimal, or fraction standards and was measured using the Snellen chart (seven studies), Glasgow acuity chart (one study), ETDRS chart (one study), or subjective vision (one study). One study considered as VI a visual acuity less than 20/80 and analyzed visual function with the VF-14 score, which records the degree of deficiency in vision affecting-daily activities, and visual acuity to high and low contrast ${ }^{(21)}$. Another study analyzed three groups: one with no VI (visual acuity of $6 / 6$ or better), one with

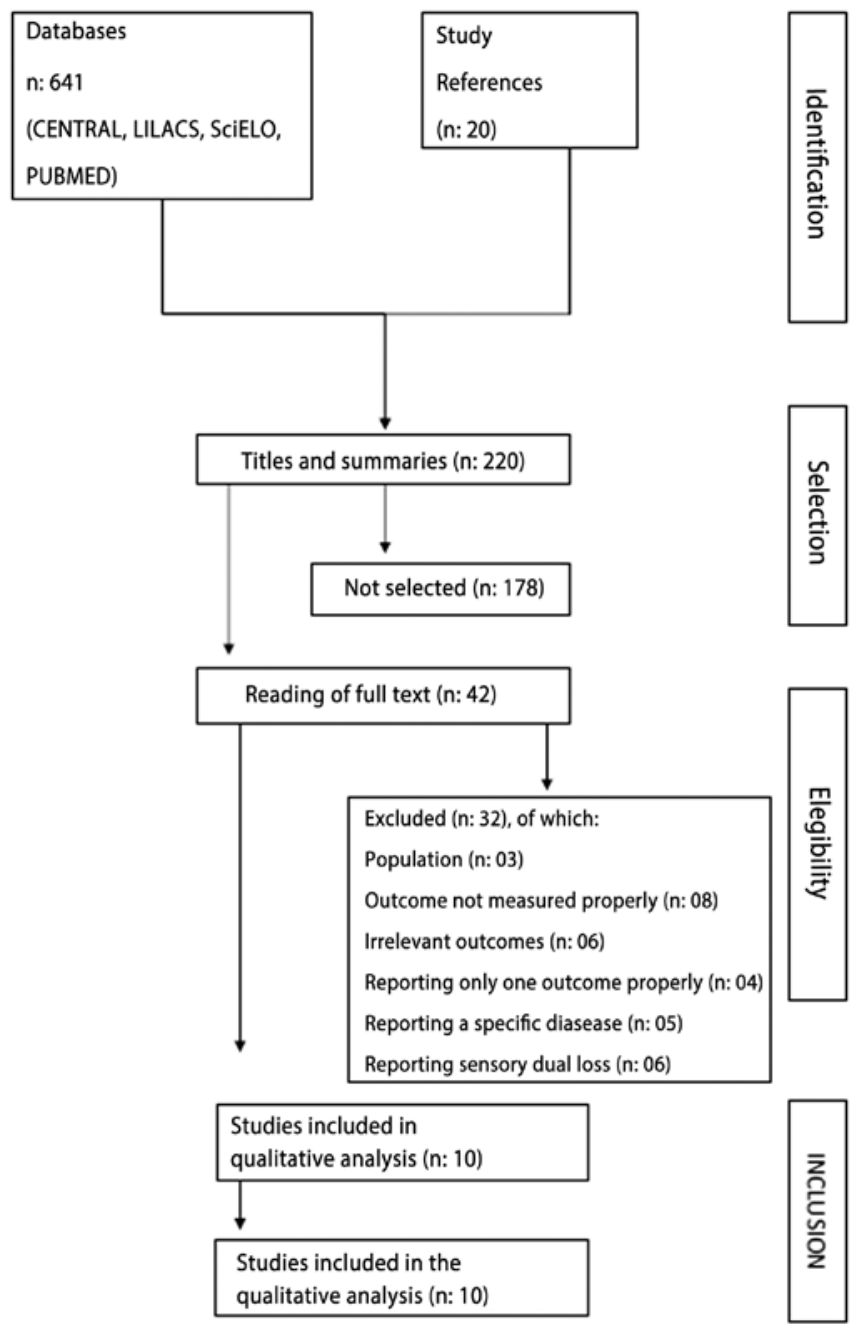

Figure 1. Flow diagram summarizing the process for selecting original articles for review. 
Table 1. Factors associated with depression in the elderly according to observational studies

\begin{tabular}{|c|c|c|c|c|c|c|}
\hline Author, year & Study design & $\begin{array}{l}\text { Continuous } \\
\text { outcomes }\end{array}$ & $\begin{array}{l}\text { Categorical } \\
\text { outcomes }\end{array}$ & $\begin{array}{c}\text { Associated to } \\
\text { depression }\end{array}$ & $\begin{array}{c}\text { Not associated to } \\
\text { depression }\end{array}$ & Study limitations \\
\hline Rovner, $1996^{(27)}$ & $\begin{array}{l}\text { Panel study (2 year } \\
\text { follow-up) }\end{array}$ & $\begin{array}{l}\text { Age, education, } \\
\text { diseases, time of } V I, \\
\text { depression, disability }\end{array}$ & $\begin{array}{l}\text { Depression (GDS), } \\
\text { disability (CD score) }\end{array}$ & VI, disability & $\begin{array}{l}\text { Neither of other } \\
\text { variables had } \\
\text { association }\end{array}$ & $\begin{array}{l}\text { Small sample; only } \\
\text { analyses distant VA, no } \\
\text { specific disability scale, } \\
\text { cross-sectional }\end{array}$ \\
\hline Rovner, $1998^{(12)}$ & Transversal & $\begin{array}{l}\text { Age, gender, education, } \\
\text { race, VI, limitations in } \\
\text { daily activities }\end{array}$ & Depression & Disability & Education & $\begin{array}{l}\text { Cross-sectional small } \\
\text { sample }\end{array}$ \\
\hline Ip, $2000^{(4)}$ & Transversal & $\begin{array}{c}\text { Age, time of } \\
\text { institutionalization, } \\
\text { duration of } \mathrm{Vl} \text {, disability }\end{array}$ & Depression & Severity of VI & Duration of blindness & Not described \\
\hline Tsai, $2003^{(23)}$ & $\begin{array}{l}\text { Population-based } \\
\text { survey }\end{array}$ & Age, education, & $\begin{array}{c}\text { Cardiovascular } \\
\text { diseases, gender, VI, } \\
\text { stroke, DM }\end{array}$ & $\begin{array}{c}\text { Age, gender, } \\
\text { cardiovascular disease, } \\
\text { stroke }\end{array}$ & Education & $\begin{array}{l}\text { Lack of specialized } \\
\text { psychiatric avaliation; } \\
\text { other diseases and } \\
\text { medications not analyzed }\end{array}$ \\
\hline Haymann, 2007(21) & Cross-sectional & $\begin{array}{l}\text { Age, gender, education, } \\
\text { race, VI, instrumental } \\
\text { activities of daily living }\end{array}$ & Depression (mCES-D) & $\begin{array}{l}\text { Physical function, visual } \\
\text { function, anxiety }\end{array}$ & $\begin{array}{l}\text { Age, gender, living } \\
\text { situation, ethnicity, } \\
\text { antidepressant }\end{array}$ & $\begin{array}{l}\text { Cross sectional; not } \\
\text { enough participants, over } \\
\text { reported disability }\end{array}$ \\
\hline Evans, 2007(24) & Cross sectional & Age, VA & Depression, anxiety & VI & Anxiety & Cross sectional \\
\hline Tournier, 2008 ${ }^{(28)}$ & $\begin{array}{l}\text { Retrospective fixed } \\
\text { cohort study }\end{array}$ & Age, chronic disease & Depression mortality & $\begin{array}{l}\text { VI, previous history of } \\
\text { depression }\end{array}$ & Severity of vision loss & $\begin{array}{l}\text { Use of databases, Cohort } \\
\text { based on the date of } \\
\text { diagnosis, VI may have } \\
\text { started before, patients not } \\
\text { followed regularly }\end{array}$ \\
\hline Noran, 2009(25) & Transversal & $\begin{array}{l}\text { Age, gender, ethnic } \\
\text { group, education, } \\
\text { marital status, } \mathrm{VI} \text {, } \\
\text { duration of } \mathrm{VI}\end{array}$ & Depression (GDS) & Severity of VI, & Don't describe & Cross-sectional \\
\hline Popescu, $2012^{(22)}$ & Cohort & $\begin{array}{l}\text { Age, binocular VA, visual } \\
\text { field, mini mental score, } \\
\text { life space assessment }\end{array}$ & Depression & $\begin{array}{l}\text { ARMD, glaucoma, and } \\
\text { Fuchs distrophy }\end{array}$ & Mean age, ethnicity & $\begin{array}{l}\text { Not longitudinal, depression } \\
\text { limit in GDS was } 5.0\end{array}$ \\
\hline Carrière, 2013(26) & Cohort & $\begin{array}{l}\text { VI, socio-demographic, } \\
\text { and clinical variables }\end{array}$ & Depression & Baseline loss & $\begin{array}{l}\text { 2-year decrease in } \\
\text { distance VA }\end{array}$ & $\begin{array}{c}\text { Functional vision was } \\
\text { poorly measured }\end{array}$ \\
\hline
\end{tabular}

$\mathrm{VI}=$ visual impairment; $\mathrm{VA}=$ visual acuity; $\mathrm{DM}=$ diabetes mellitus.

Table 2. Avaliation of bias risk using the adapted Newcastle-Ottawa Scale ${ }^{(20)}$

\begin{tabular}{|c|c|c|c|c|c|}
\hline Article (year) & $\begin{array}{c}\text { Acessing independent } \\
\text { variables }\end{array}$ & $\begin{array}{c}\text { Is depression } \\
\text { avaliation adequate? }\end{array}$ & Sample representivity & Participants selection & $\begin{array}{l}\text { Definition of control } \\
\text { group or cohort* }\end{array}$ \\
\hline Rovner (1996) $)^{(17)}$ & $H$ & $\mathrm{~L}$ & $\mathrm{H}$ & $\mathrm{H}$ & $U$ \\
\hline Rovner (1998) $)^{(12)}$ & $\mathrm{H}$ & 1 & $L$ & $L$ & - \\
\hline $\operatorname{lp}(2000)^{(4)}$ & $L$ & $\mathrm{~L}$ & $U$ & $\mathrm{H}$ & - \\
\hline Tsai $(2003)^{(23)}$ & $L$ & $U$ & $L$ & $L$ & 1 \\
\hline Haymann $(2007)^{(21)}$ & $\mathrm{H}$ & $\mathrm{L}$ & $\mathrm{H}$ & $\mathrm{H}$ & - \\
\hline Evans $(2007)^{(24)}$ & $\mathrm{L}$ & $\mathrm{L}$ & $L$ & $L$ & - \\
\hline Tournier $(2008)^{(28)}$ & $L$ & $U$ & $L$ & $L$ & $L$ \\
\hline Noran $(2009)^{(25)}$ & $\mathrm{L}$ & $\mathrm{L}$ & $\mathrm{L}$ & $\mathrm{H}$ & - \\
\hline Popescu (2012)(22) & $L$ & $\mathrm{~L}$ & $\mathrm{H}$ & $\mathrm{H}$ & $U$ \\
\hline Carrière $(2013)^{(26)}$ & $\mathrm{L}$ & $U$ & $\mathrm{~L}$ & $\mathrm{~L}$ & $L$ \\
\hline
\end{tabular}

$\mathrm{L}=$ low risk of bias; $\mathrm{U}=$ uncertain risk of bias; $\mathrm{H}=$ high risk of bias.

* = only for longitudinal studies.

moderate VI (6/6 to $6 / 18)$, and one with worse VI (worse than $6 / 18$ or 20/60)(24). Some studies considered visual acuity less than 20/70 (based on ICD-9 and -10) as V|(4,23,25); however, only one study measured near and distant visual acuities ${ }^{(4)}$. Two studies considered VI as visual acuity less than 20/40 or visual field defects ${ }^{(22,23)}$. One study analyzed blindness (visual acuity of 20/400 or worse) ${ }^{(26)}$ and another analyzed visual loss with a subjective questionnaire of self-reported activities that the person can or cannot answer because of his vision ${ }^{(12)}$; it was not possible to perform meta-analysis with this variable because visual acuity was measured using different methods in each article.

\section{Depression and Visual impairment}

Despite heterogeneity between the groups of visually impaired subjects and the group of depressed subjects, it was not possible to perform statistical analysis.

\section{ANXIETY AND DEPRESSION}

Anxiety was just analyzed in two studies. In one study, it was recorded using STAI-6 and was associated with VI and depression (21). Another study used GHQ-28(24) to analyze anxiety, and it was not possible to perform meta-analysis. 


\section{QUALITY OF LIFE AND DEPRESSION}

Quality of life was analyzed in one study ${ }^{(21)}$ by the SF-36 score and had an association with depression with regard to a low quality-of-life score. SF-36 generates a Mental Component Summary (MCS) and a Physical Component Summary (PCS) score. SF-36 can also be considered a disability measure because the questions are worded to reflect limitation in ability related to health issues.

\section{LIMITATION IN DAILY ACTIVITIES AND DEPRESSION}

A limitation in daily activities and depression was measured using the Nottingham Extended Activities of Daily Living Index (NEADL) in one study ${ }^{(21)}$. In this scale, a low score suggests that the person is dependent in his activities. In another study, ADL was used ${ }^{(12)}$.

\section{Physical activity and depression}

This variable was measured in only one study ${ }^{(21)}$ using the Human Activity Profile (HAP), which records the respondent's highest level of energy expenditure and generates the maximum activity score.

\section{DISABILITY AND DEPRESSION}

Mobility in one study was measured using the Life Space assessment (LS-C-120), a questionnaire that records the frequency of going to different level spaces at home and outside in a month ${ }^{(22)}$. Disability was also analyzed in one study ${ }^{(27)}$ using CDS-30 and in another using the Oregon Administrative Rules (OAR) instrument ${ }^{(12)}$. It was impossible to perform meta-analysis for this factor.

\section{Mortality AND DEPRESSION}

Mortality and depression was analyzed only in one study ${ }^{(28)}$, because of this, it was not possible to perform meta-analysis.

\section{Chronic diseases and other comorbidities in Depression}

Two studies reported an association between chronic diseases and depression, measured using CDS; another study just analyzed specific diseases such as diabetes, cardiovascular diseases, and stroke ${ }^{(23,28)}$ using two different methods; therefore, it was not possible perform statistical analysis.

\section{OCular diseases AND dePression}

One study compared three ocular diseases as the cause of $\mathrm{VI}^{(22)}$. Age-related macular degeneration (ARMD) was compared in two other studies to the prevalence of other ocular diseases (ARMD 61.4\%, cataract $31.4 \%$, glaucoma $21.4 \%$, diabetic retinopathy $15.7 \%$, and others $5.7 \%)$ in visually impaired participants ${ }^{(21,27)}$. Therefore, it was not possible to compare these different data.

\section{RISK OF BIAS IN THE ARTICLES}

Most articles had $\mathrm{L}$ and $\mathrm{U}$ (low and uncertain risk) in the major items of the quality scale used. The risk of bias in the studies included is summarized in table 2.

\section{DISCUSSION}

Depression is a major public health concern among the elderly. It causes suffering, family disruption, disability, worsening of the outcome of many medical illnesses, and increased mortality ${ }^{(29)}$. The prevalence of depression among the elderly varies. Almost 3\% of the general elderly population suffers from major depression; $8 \%-16 \%$ of the elderly have clinically significant depressive symptoms ${ }^{(30)}$.

Rates of $\mathrm{VI}$ in the elderly increase with age and are associated with functional loss, mortality as well as psychological distress, sense of loneliness, and depression. Given that depression is treatable and some ocular diseases that cause visual loss are reversible, early identification and treatment of persons most at a risk could have an important impact in the well-being of the elderly ${ }^{(26)}$.
The studies included in this review were observational, with half of them being cross-sectional, and these study designs do not show causality. Therefore, it is difficult to confirm a temporal relationship between depression and VI. The limitations of this review were the inadequate definition of outcomes and lack of responses by some authors regarding missing data.

The sociodemographic variables were not associated with depression in most articles. In one study, men were more depressed than women ${ }^{(28)}$. In another, women had a higher incidence of depression than men ${ }^{(23)}$. Another study showed that a low level of education is associated with greater symptoms of depression ${ }^{(25)}$.

The outcome depression was analyzed using GDS-15 in six studies $^{(4,21,24,25,27,28)}$; nevertheless, the cut-off for depression varied in these studies, limiting the comparison between heterogeneous groups.

Only one study analyzed a previous history of depression or the use of antidepressant medicine, which is, by itself, a risk factor for depression ${ }^{(28)}$.

Depression was related to $\mathrm{VI}$ in all studies (prevalence ranged from $8.8 \%$ to $45.2 \%$ ).

Visual acuity was accessed using different methods (Snellen, Glasgow, and ETDRS), and only one study ${ }^{(21)}$ evaluated the Visual Function Score (VF-14), and this variable was associated with depression. The same study also assessed high- and low-contrast visual acuity, and both were related to more depression. Only one article assessed near and far visual acuity ${ }^{(26)}$ and found that only far visual acuity was associated with depression.

Most articles used the best-corrected visual acuity; nevertheless, just one article ${ }^{(23)}$ related that refraction was done when visual acuity was low, considering that refractive errors are reversible $\mathrm{V}{ }^{(31)}$.

The criteria to determine VI varied between the studies. One study used ICD-9(28), while another used ICD-10(25). Most articles did not establish standard criteria to diagnose VI. Consequently, there was a high heterogeneity between the $\mathrm{VI}$ groups, ranging between worse than $20 / 40^{(23,24)}$ and worse than $20 / 70^{(25)}$.

The relationship between severity of $\mathrm{VI}$ and depression was just reported by two studies ${ }^{(4,25)}$. One study found that the severity of visual loss does not matter and that VI was a risk factor for depression only in participants without a previous history of depression, and this study found that a 2-year history of depression is the most important risk indicator of depression (28). The other study found that there is a positive association of more severe visual loss with depression ${ }^{(25)}$.

One study used a questionnaire with subjective questions about the vision of the participant and what the participant was and was not able to do because of the visual loss. This type of questionnaire could be a risk because there is no objective method to measure the real visual acuity in these cases $^{(27)}$.

Only two authors evaluated baseline and follow-up visual acuities, and they found that the follow-up visual loss was associated with depression ${ }^{(26,27)}$. The two studies that analyzed the time of visual loss and depression found different results ${ }^{(4,25)}$.

Anxiety was analyzed by two authors, and one found a relationship between anxiety and depression and Vl; however, the other did not described such an association ${ }^{(21,24)}$.

Other variables (quality of life, limitation of diary activities, physical activities, and disability) that were previously considered as very important in the association between $\mathrm{VI}$ and depression were correlated with depression; nevertheless, they were analyzed in only few studies ${ }^{(21)}$. When advanced age is coupled with low vision, a person's level of activity is narrowed further than with either age or VI alone. Furthermore, although older people can normally adjust well to environmental challenges, when the demands on their body are increased, such as when vision is disrupted, physical limitations may become problematic and affect quality of life(21).

The limitation of daily activities was analyzed in two studies, measured using different methods, and it was associated with depression in $\operatorname{both}^{(21,27)}$. 
In one study (24), the author reported that a high limitation in daily activities is associated with an eight times greater $\mathrm{VI}$ and 12 times more depressed people.

One study ${ }^{(26)}$ reported that the time of institutionalization, when it occurs, is not related with depression. In addition, one study related that living alone is not associated with an increase in depression rates ${ }^{(21)}$.

Disability is already well known in the literature as an important risk factor for $\mathrm{VI}$ and depression ${ }^{(2)}$, and it is a major public health issue for the elderly. Age is associated with decreased physical competence and increased prevalence of chronic illness ${ }^{(21)}$. VI is an important, but not life threatening, chronic illness and cause of disability ${ }^{(32)}$ and has been associated with depression in three studies ${ }^{(12,22,27)}$. Different indices were used to assess disability. Low functional ability was associated with depression in one study, as measured using the Barthel index ${ }^{(25)}$.

Mortality and chronic diseases were described in one and two studies, respectively ${ }^{(23,28)}$; both associated this factor with depression, and these factors are also described in the literature as being im-

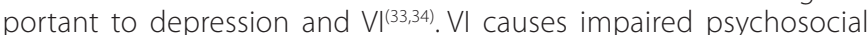
functioning with impaired ADL, loss of independence, reduced social interaction, and depression, and it is known to be related to mortality. In addition, patients may be exposed to shared risk factors for mortality and VI, such as aging, diabetes, vascular pathology, high blood pressure, or smoking ${ }^{(28)}$.

Chronic diseases were assessed by the CDC score in one study and were associated with depression and Vl; another study reported that stroke and cardiovascular diseases are related to depression ${ }^{(23,28)}$ and there is a strong association in the literature with these risk factors ${ }^{(18)}$

The causes of VI were described in one study ${ }^{(22)}$, which demonstrated that diseases that cause central visual loss are more associated with depression than those that present with peripheral visual loss. Another study just reported the prevalence of the diseases ${ }^{(27)}$ without specifying whether any of them is associated with depression. None of the articles classified ocular disease as being reversible or permanent, which could have been important in determining whether a person with an irreversible disease had more or less depression than one with a reversible cause.

The implication with regard to clinical practice is that because there is no established link between standardized VI measurements and depression, physicians would have to rely on knowledge and clinical experience to decide when to investigate and treat a depressed visually impaired patient.

This review shows that new research is necessary to analyze each important variable because most studies did not include the full range of common risk factors for both $\mathrm{VI}$ and depression, making it impossible to establish a linear correlation between them. In addition, it is important to use standard criteria to classify depression and $\mathrm{VI}$, such as the GDS scale with a standard cut-off to depression and VI criteria following just IDC or WHO.

\section{CONCLUSIONS}

After a literature research, we could not definitely establish an association between $\mathrm{VI}$ and depression in the elderly. The reasons include a lack of standardized measures of $\mathrm{VI}$ and depression to allow comparability of the studies and the potential bias created by several other variables.

\section{REFERENCES}

1. Mann E, Koller M, Mann C, van der Cam- men T, Steurer J. Comprehensive geriatric assessment (CGA) in general prac- tice: results from a pilot study in Vorarl- berg, Austria. BMC Geriatr. 2004:4:4

2. Cacciatore F, Abete P, Maggi S, Luchetti G, Calabrese C, Viati L, et al. Disability and 6-year mortality in elderly population. Role of visual impairment. Aging Clin Exp Res. 2004; 16(5):382-8.

3. Iliffe S, Kharicha K, Harari D, Swift C, Gillmann G, Stuck A. Self-reported visual function in healthy older people in Britain: an exploratory study of associations with age, sex, depression, education and income. Fam Pract. 2005;22(6):585-90.
4. Ip SP, Leung YF, Mak WP. Depression in institutionalised older people with impaired vision. Int J Geriatr Psychiatry. 2000;15(12):1120-4

5. Bruce ML, Hoff RA. Social and physical health risk factors for first- onset major depressive disorder in a community sample. Soc Psychiatry Psychiatr Epidemiol. 1994; 29(4):165-71.

6. Galariall, Casten RJ, Rovner BW. Development of a shorter version of the geriatric depression scale for visually impaired older patients. Int Psychogeriatr. 2000;12(4):435-43.

7. World Health Organization - WHO. The global burden of disease. Geneva: WHO; 2004; Update (2008).

8. Rovner BW, Shmuely-Dulitzki Y. Screening for depression in low-vision elderly. Int J Geriatr Psychiatry. 1997;12(9):955-9.

9. Evans JR, Fletcher AE, Wormald RP, Ng ES, Stirling S, Smeeth L, et al. Prevalence of visual impairment in people aged 75 years and older in Britain: results from the MRC trial of assessment and management of older people in the community. $\mathrm{Br} J$ Ophthalmol. 2002;86(7):795-800

10. Carabellese C, Appollonio I, Rozzini R, Bianchetti A, Frisoni GB, Frattola L,et al. Sensory impairment and quality of life in a community elderly population. J Am Geriatr Soc. 1993;41(4):401-7.

11. Woo J, Ho SC, Lau J, Yuen YK, Chiu H, Lee HC, et al. The prevalence of depressive symptoms and predisposing factors in an elderly Chinese population. Acta Psychiatr Scand. 1994;89:8-13.

12. Rovner BW, Ganguli M. Depression and disability associated with impaired vision: the MoVies Project. J Am Geriatr Soc. 1998;46(5):617-9.

13. Rovner BW, Shmuely-Dulitzki Y. Screening for depression inlow-vision elderly. Int J Geriatr Psychiatry. 1997:12(9):955-9.

14. Wahl HW, HeylV, Oswald F, Winkler U. [Deteriorating visionin the elderly: double stress?]. Ophthalmologe. 1998;95(6):389-99. German.

15. Moher D, Liberati A, Tetzlaff J, Altman DG, PRISMA Group: Preferred reporting items for systematic reviews and meta-analyses: the PRISMA statement. Ann Intern Med. 2009;151(4):264-9, W64

16. Dandona L, Dandona R. Revision of visual impairment definitions in the International Statistical Classification of Diseases. BMC Med. 2006 16;4:7.

17. Yesavage JA, BrinkTL, Rose TL, Lum O, Huang V, Adey M, Leirer VO. Development and validation of a geriatric depression screening scale: a preliminary report. J Psychiatr Res. 1982;17(1):37-49

18. Radloff L. The CES-D scale: a self-report depression scale for research in the general population. Appl Psychol Measurement. 1977;1:385-401.

19. Mello AC, Engstrom EM, Alves LC. Fatores sociodemográficos e de saúde associados à fragilidade em idosos: uma revisão sistemática de literatura. Cad Saúde Pública, 2014; 30(6):1143-1168.

20. Wells GA, Shea B, O'Connell D, Peterson J, Welch V, Losos M, Tugwell P. The Newcastle-Ottawa Scale (NOS) for assessing the quality of nonrandomized studies in meta-analyses [Internet] [cited 2013 May 20. Available from: http://www.ohri.ca/programs/ clinical_epidemiology/oxford.asp.

21. Hayman KJ, Kerse NM, La Grow SJ, Wouldes T, Robertson MC, Campbell AJ. Depression in older people: visual impairment and subjective ratings of health. Optom Vis Sci. 2007;84(11):1024-30.

22. Popescu ML, Boisjoly H, Schmaltz H, Kergoat MJ, Rousseau J, Moghadaszadeh S, et al. Explaining the relationship between three eye diseases and depressive symptoms in older adults. Invest Ophthalmol Vis Sci. 2012;53(4):2308-13.

23. Tsai SY, Cheng CY, Hsu WM, Su TP, Liu JH, Chou P. Association between visual impairment and depression in the elderly. J Formos Med Assoc. 2003;102(2):86-90.

24. Evans JR, Fletcher AE, Wormald RP. Depression and anxiety in visually impaired older people. Ophthalmology. 2007:114(2):283-8.

25. Noran NH, Izzuna MG, Bulgiba AM, Mimiwati Z, Ayu SM. Severity of visual impairment and depression among elderly Malaysians. Asia Pac J Public Health. 2009:21(1):43-50.

26. Carrière I, Delcourt C, Daien V, Pérès K, Féart C, Berr C, et al. A prospective study of the bi-directional association between vision loss and depression in the elderly. J Affect Disord. 2013;151(1):164-70.

27. Rovner, B. W., Zisselman, P. M., \& Shmuely-Dulitzki, Y. Depression and disability in older people with impaired vision: a follow-up study. Journal of the American Geriatrics Society. 1996;44(2):181-4

28. Tournier M, Moride Y, Ducruet T, Moshyk A, Rochon S. Depression and mortality in the visually-impaired, community-dwelling, elderly population of Quebec. Acta Ophthalmol. 2008;86(2):196-201.

29. Alexopoulos GS. Depression in the elderly. Lancet. 2005:365(9475):1961-70.

30. World Health Organization - WHO. The World Health Report. Mental Health: New Understanding, New Hope. Geneva, Switzerland: WHO; 2001.

31. Schellini SA, Hoyama E, Cordeiro R, Padovani CR. The prevalence of low vision and blindness in a randon brazilian sample [abstract]. In: ARVO - Annual Meeting; 2006, Fort Lauderdale (FL): Abr 30-Maio 4. v.1. p.47.

32. Brody BL, Roch-Levecq AC, Gamst AC, Maclean K, Kaplan RM, Brown SI. Self-management of age-related macular degeneration and quality of life: a randomized controlled trial. Arch Ophthalmol. 2002;120(11):1477-83.

33. Thiagarajan M, Evans JR, Smeeth L, Wormald RP, Fletcher AE. Cause-specific visual impairment and mortality: results from a population-based study of older people in the United Kingdom. Arch Ophthalmol. 2005:123(10):1397-403.

34. Wang JJ, Mitchell P, Simpson JM, Cumming RG, Smith W. Visual impairment, age-related cataract, and mortality. Arch Ophthalmol. 2001;119(8):1186-90. 